\title{
Por uma educação mais positiva - Psicologia Positiva aplicada à educação
}

DOI: $10.5935 / 1984-9044.20200030$

\section{Jonatã Silva de Oliveira - Universidade Federal de São Carlos (UFSCar)}

Resumo: A Psicologia Positiva é uma abordagem psicológica originada no início deste século que propõe o estudo científico dos aspectos positivos das características humanas e do sentimento de realização perante a vida. A obra Psicologia positiva aplicada a educação, organizada por Tatiana de Cássia Nakano, com a contribuicão de diversos especialistas, apresenta como essa vertente recente pode potencializar os processos de aprendizagens e relacionais dos diferentes aspectos envolvidos na educação. Os treze capítulos do livro abordam temas como desenvolvimento positivo, qualidade de vida, projeto de vida, competências socioemocionais, criatividade, atitudes positivas, entre outros construtos correlatos a esses temas ligados aos processos do ambiente educacional. Há também capítulos dedicados a pesquisas autorais sobre os aspectos pertinentes a essa temática. O livro vislumbra o panorama das pesquisas e intervenções mais recentes relacionadas ao tema da educação e pode ser atrativo aos pesquisadores da área da educação e da psicologia e aos profissionais do campo educacional.

PALAVRAS-CHAVE: Psicologia Positiva; desenvolvimento humano; psicologia educacional; qualidade de vida.

\section{For a education more positive - Positive Psychology applied to education}

\begin{abstract}
The Positive Psychology is a psychological approach origined in the begin this century that proposes the scientifical study of the positive human characteristics and of realization towards to life feeling. The work "Positive psychology applied to education", organized by Tatiana de Cássia Nakano and contributed by several specialists, shows how this recent strand can potencialize the learning and relationals processes to differents aspects involved to the education. The thirteen chapters of book embraces themes as positive development, quality of life, life project, socioemotional compentences, criativity, positive atittudes, between others correlated constructs related to the educational environment processes. There is also chapters dedicateds to autoral researches more recents relationed about the pertinent aspects to this thematic. The book glimpse the panorama of the researches and interventions most recents relationed to the theme of education and can be attractive to the researchers of education,psychology area and educational field professionals.
\end{abstract}

KEY WORDS: Positive Psychology; human development; educational psychology; quality of life 
Psicologia Positiva se constitui por teorias e pesquisas a respeito das características positivas de indivíduos e instituições e, cientificamente, se propõe a compreender uma das questões pertinentes à filosofia: o que faz a vida valer a pena? (Noble e McGrath, 2008, Seligman, Steen, Park e Peterson, 2005). Especialmente, foca-se nos domínios das emoções, motivações, relações sociais, competências, expectativas, forças de caráter, nas teorias do bem-estar, no conceito flow, entre outros construtos no intuito de promover o florescimento, um estado de bem-estar psicológico quanto a si e quanto ao rumo de sua própria vida (ver Modelo PERMA, Seligman, 2011, Gable e Haidt, 2005; Seligman e Csikszentmihalyi, 2000).

No âmbito dessa área, organizado pela autora Tatiana de Cássia Nakano, doutora em Psicologia como Profissão e Ciência pela Pontifícia Universidade Católica de Campinas (PUC-Camp) e pósdoutora pela Universidade São Francisco, o livro Psicologia Positiva Aplicada à Educação reúne a contribuição de 34 profissionais e pesquisadores de diferentes áreas da psicologia, em 13 capítulos que abordam, de maneira aplicada ao contexto educacional e a diferentes grupos demográficos, teorias e conceitos pertinentes à abordagem vigente. Em sua primeira edição, lançada em 2018, a obra pode ser dividida (de modo não linear) em alguns temas: desenvolvimento positivo, qualidade de vida e projeto de vida (capítulos 2, 3 e 5), competências socioemocionais otimismo ( 6 e 7), fatores influenciadores ao desempenho escolar (7 e 10), forças de caráter (8), criatividade $(9,11$ e 12) e atitudes positivas (13). O Capítulo 1, ao contrário dos demais, é mais abrangente e introduz o leitor à obra dissertando sobre as aplicações e possibilidades da Psicologia Positiva (e alguns de seus conceitos), citando, inclusive, breves exemplos de protocolos de intervenção no contexto educacional.

Em uma perspectiva da estrutura geral dos capítulos, a forma como foram dissertados mostra semelhança com o estilo de um artigo científico. Em alguns capítulos, além dessa fase de revisão da literatura, os autores publicaram seus próprios estudos, originais e voltados a 
investigar uma particularidade do tema. A equipe de autores é composta por uma notável diversidade de especializações, e a construção do livro demonstra como a psicologia positiva se fortifica através da interdisciplinaridade. Desse modo, o leitor poderá se deparar com construtos e teorias de outros paradigmas da psicologia, como, por exemplo, pelo conceito ecológico do desenvolvimento humano de Bronfenbrenner, presente no capítulo 10, para auxiliar no entendimento dos impactos de fatores psicossociais relacionados à violência no desempenho escolar dos jovens.

Por outro lado, uma das observações praticamente unânimes entre todos os capítulos é a de que o tema ou construto em questão não possui ainda um consenso da comunidade científica quanto à sua operacionalização. No entanto, os autores procuraram elucidar os avanços dos estudos, principalmente destacando o que existe de consenso entre os principais autores sobre o tema. De toda forma, revela-se que o trabalho de investigação sobre esses construtos é complexo e demanda uma visão holística dos fenômenos a ele relacionados, tornando-se ainda mais bem-vinda a interdisciplinaridade na psicologia positiva.

Embora em poucos casos, como o dos capítulos direcionados ao otimismo, as considerações das limitações contemporâneas dessa área foram abordadas de maneira mais tímida. Em outros capítulos, constata-se que existem lacunas, por exemplo, quanto à efetividade de intervenções baseadas em competências socioemocionais nos contextos educacionais (e apenas um pequeno contingente de pesquisadores intencionados em investigar isso), conforme apresentado no capítulo 3, ou também quanto à ausência de pesquisas empíricas para avaliar programas de promoção do Desenvolvimento Juvenil Positivo através do esporte, empregados no contexto brasileiro. Ou, ainda, quanto à investigação dos aspectos da duplicidade excepcional em educandos, crucial para delinear intervenções e políticas públicas de inclusão na educação, permitindo contemplar não somente os déficits apresentados como também as potencialidades específicas que essa população possui. Abordar as 
limitações de uma área é essencial para estimular que outros profissionais participem da prática científica, principalmente em uma área emergente como é o caso da psicologia positiva, além do óbvio benefício que trará ao desenvolvimento de uma educação mais inclusiva e enriquecedora ao público alvo.

Falar criticamente de Educação significa trabalhar com assuntos como de políticas públicas, de inclusão social, de desenvolvimento humano, de sistemas sociais, de cultura, de atitudes, das avaliações, de relações interpessoais, de violência, de gênero, entre outras dimensões que elucidam como o tema da educação é complexo e extrapola os limites de uma sala de aula. A obra é capaz de fornecer reflexões e pontos de partida para ações concretas através da perspectiva de que uma instituição de ensino não se restringe, tradicionalmente, apenas aos objetivos acadêmicos, mas também aos de desenvolver outras competências críticas (no escopo emocional, ético e cidadão) para o seu estágio atual e futuro. Além disso, oferece insumos para educadores repensarem as metas educacionais de suas instituições.

Considerando a cada vez maior demanda de acesso aos serviços de saúde mental para crianças e adolescentes nos últimos tempos, influindo até mesmo em aspectos como a evasão e repetência escolar dos alunos da tão desigual educação brasileira (Silva Filho; Araújo, 2017), o livro estimula a compreender o espaço escolar como um local estratégico para a implementação de políticas preventivas para a saúde e de potencialização do bem-estar (Green et al., 2011).

Devem ser comentadas aqui algumas limitações provenientes dessa primeira edição. Por exemplo, há alguns (poucos) erros de natureza editorial, relacionados à digitação ou construção de frases. Também pode haver a impressão de que a parcimônia precise ser mais bem empregada no conjunto da obra, quanto à repetição de explanações de uma mesma informação. Outra questão diz respeito ao fato de que capítulos que apresentam pesquisas empíricas podem ser compreendidos pelo leitor com menos facilidade, quer pela exposição de 
extensas tabelas e valores estatísticos, quer pela sua estrutura em formato de artigo acadêmico. Por outro lado, essa característica, assim como a estratégia de revisão da literatura para sustentar os argumentos dos autores, pode ser muito atrativa para estudantes, pesquisadores e profissionais de psicologia e da área da educação mais familiarizados com a linguagem e prática científicas, sendo positivo para essa área que demanda o trabalho de investigação para muitas de suas lacunas.

\section{Referências}

Gable, S. \& Haidt, J. (2005). What (and why) is positive psychology? Review of General Psychology, 9(2), 103-110. doi: 10.1037/1089-2680.9.2.103. Acesso em: 7 set 2020.

Green, S., Oades, L. \& Robinson, P. (2011). Positive education: Creating flourishing students, staff and schools. In Psych. 33. 16-18.

Nakano, T. de C. (2017). Psicologia positiva aplicada a educação. São Paulo: Vetor Editora.

Noble, T. \& McGrath, H. (2008). The positive educational practices framework: A tool for facilitating the work of educational psychologists in promoting pupil wellbeing. Educational and Child Psychology, 25, 119-134. Disponível em: < https://psycnet.apa.org/record/2009-06944-011> Acesso em: 7 set 2020.

Seligman, M., Steen, T., Park, N. \& Peterson, C. (2005). Positive psychology progress: empirical validation of interventions. American Psychologist, 60(5), 410. doi:10.1037/0003-066X.60.5.410. Acesso em: 7 set 2020. 
POR UMA EDUCAÇÃO MAIS POSITIVA - PSICOLOGIA POSITIVA APLICADA À EDUCAÇÃO

Seligman, M. (2011). Florescer: Uma nova compreensão sobre a natureza da felicidade e do bem-estar. Rio de Janeiro: Objetiva.

Silva Filho, R. \& Araújo, R. (2017). Evasão e abandono escolar na educação básica no Brasil: fatores, causas e possíveis consequências. Educação Por Escrito.

doi: 8. 35. 10.15448/2179-8435.2017.1.24527. Acesso em: 3 dez 2020

Recebido em: 14/08/2020

Aprovado em: 02/12/2020 